\title{
Thermal infrared reflectance and emission spectroscopy of quartzofeldspathic glasses
}

\author{
Jeffrey M. Byrnes, ${ }^{1}$ Michael S. Ramsey, ${ }^{2}$ Penelope L. King, ${ }^{3}$ and Rachel J. Lee ${ }^{2}$ \\ Received 21 August 2006; revised 27 October 2006; accepted 17 November 2006; published 10 January 2007.
}

[1] This investigation seeks to better understand the thermal infrared (TIR) spectral characteristics of naturallyoccurring amorphous materials through laboratory synthesis and analysis of glasses. Because spectra of glass phases differ markedly from their mineral counterparts, examination of glasses is important to accurately determine the composition of amorphous surface materials using remote sensing datasets. Quantitatively characterizing TIR $(5-25 \mu \mathrm{m})$ spectral changes that accompany structural changes between glasses and mineral crystals provides the means to understand natural glasses on Earth and Mars. A suite of glasses with compositions analogous to common terrestrial volcanic glasses was created and analyzed using TIR reflectance and emission techniques. Documented spectral characteristics provide a basis for comparison with TIR spectra of other amorphous materials (glasses, clays, etc.). Our results provide the means to better detect and characterize glasses associated with terrestrial volcanoes, as well as contribute toward understanding the nature of amorphous silicates detected on Mars. Citation: Byrnes, J. M., M. S. Ramsey, P. L. King, and R. J. Lee (2007), Thermal infrared reflectance and emission spectroscopy of quartzofeldspathic glasses, Geophys. Res. Lett., 34, L01306, doi:10.1029/2006GL027893.

\section{Introduction}

[2] Thermal infrared (TIR) remote sensing (including laboratory spectroscopy) provides an effective, quantitative means to remotely and non-destructively analyze the surfaces of geologic materials. The TIR energy emitted by these materials is dependent on both the radiant temperature and the material's emissivity $(\varepsilon)$, a fundamental property that is a function of chemical bonding and varies with wavelength [e.g., Hapke, 1993]. Emissivity spectra can be used to characterize physiochemical properties of geologic deposits, including material compositions and physical states [e.g., Lyon, 1965; Vincent and Thomson, 1972; Walter and Salisbury, 1989; Christensen et al., 2000], age relationships [Kahle et al., 1988; Crisp et al., 1990; Realmuto et al., 1992], and surface textures [Ramsey and Fink, 1999; Byrnes et al., 2004; Ramsey and Dehn, 2004].

[3] Laboratory TIR spectroscopy studies have investigated numerous minerals [e.g., Salisbury et al., 1991;

\footnotetext{
${ }^{1}$ Astrogeology Team, U.S. Geological Survey, Flagstaff, Arizona, USA.

${ }^{2}$ Department of Geology and Planetary Science, University of Pittsburgh, Pittsburgh, Pennsylvania, USA.

${ }^{3}$ Department of Earth Sciences, University of Western Ontario, London, Ontario, Canada.
}

Copyright 2007 by the American Geophysical Union. 0094-8276/07/2006GL027893\$05.00
Christensen et al., 2000] but relatively few silicate glasses [e.g., Nash and Salisbury, 1991; Wyatt et al., 2001; Johnson et al., 2002, 2003]. Silicate glasses are an important class to understand because they can be produced from shock-metamorphism (resulting from impacts) or melting (associated with volcanism and/or impacts). However, the paucity of knowledge of glass emissivity commonly prohibits its accurate identification. This is especially problematic because other amorphous silicates commonly have similar spectral features to those of glasses [e.g., Wyatt and McSween, 2002; Hamilton et al., 2003; Koeppen and Hamilton, 2005], especially at the low spectral resolution of many airborne and spaceborne remote sensing instruments. Common or averaged spectra of silicate glasses and shocked feldspars have been used in spectral libraries for mineral mapping on Mars [e.g., Bandfield et al., 2000; Hamilton et al., 2001; Johnson et al., 2006] and for small-scale (millimeter- to centimeter-scale) textural mapping on Earth [e.g., Ramsey and Fink, 1999; Byrnes et al., 2004; Ramsey and Dehn, 2004]. However, the results of those studies are dependant on the particular glass spectra used for identification and may be inaccurate if inappropriate end-members are used [Koeppen and Hamilton, 2005].

[4] This investigation focuses on glasses relevant to volcanic systems (i.e., glasses derived from melts rather than from shock processes) and is the initial stage of a new study that seeks to clarify precise TIR spectral distinctions associated with compositional differences of silicate glasses. Typical volcanic glasses associated with effusive eruptions on Earth vary from rhyoltic to basaltic in composition, reflecting the composition of the melt at the time the glass is quenched [e.g., Crisp et al., 1990; Ramsey and Fink, 1999]. Our approach is to investigate the TIR features of glasses made from simple end member mineral compositions (feldspars and quartz) for which TIR spectra are known. This approach is advantageous because it will provide us with a basis from which to interpret the TIR spectra of more complicated glasses in the future. We chose to investigate feldspars and quartz mixtures because these represent some of the most common minerals on the Earth's surface and make up volcanic rocks from dacites to rhyolites (and their intrusive equivalents, granodiorites to granites). Implications are considered specifically for TIR remote sensing studies of Earth and Mars because volcanic deposits are abundant on both planets and because both currently have available TIR remote sensing data with reasonably high spatial and spectral resolution.

\section{Methodology}

[5] For our laboratory studies, we synthesized and analyzed glasses relevant to common silicic volcanic lavas. Glass synthesis and spectroscopy was completed at the 
Table 1. Suite of Synthesized Glasses

\begin{tabular}{|c|c|c|c|c|c|c|}
\hline Glass Composition & Weight, \% & $\mathrm{Si} / \mathrm{O}$ Ratio & $\mathrm{Al} / \mathrm{O}$ Ratio & $\mathrm{Al} / \mathrm{Si}$ Ratio & Reflectance Maxima, $\mathrm{cm}^{-1}$ & Emissivity Minima, $\mathrm{cm}^{-1}$ \\
\hline Andesine & 100 & 0.31 & 0.19 & 0.61 & 1014 & 459,1007 \\
\hline Oligoclase & 100 & 0.36 & 0.14 & 0.40 & 1043 & 465,1043 \\
\hline Microcline & 100 & 0.37 & 0.13 & 0.36 & 1059 & 459,1063 \\
\hline Andesine/Quartz (rhyolitic) & $59 / 41$ & 0.38 & 0.12 & 0.30 & 1086 & 465,1092 \\
\hline Oligoclase/Quartz (dacitic) & $70 / 30$ & 0.39 & 0.11 & 0.28 & 1078 & 471,1088 \\
\hline Oligoclase/Quartz (rhyolitic) & $59 / 41$ & 0.42 & 0.08 & 0.21 & 1088 & 471,1093 \\
\hline
\end{tabular}

Image Visualization and Infrared Spectroscopy (IVIS) Laboratory at the University of Pittsburgh and the Experimental Analysis Laboratory at the University of Western Ontario, Canada.

\subsection{Glass Synthesis}

[6] A suite of minerals and mineral mixtures was used to synthesize glasses in the Experimental Analysis Laboratory (Table 1). End-member glasses of microcline, oligoclase, and andesine feldspars were created; glasses of quartz $\left(\mathrm{SiO}_{2}\right)$ plus plagioclase were also synthesized, including two "rhyolitic" glasses (41 wt. \% quartz +59 wt. \% plagioclase) and a "dacitic" glass (30 wt. \% quartz +70 wt. \% plagioclase). In order to synthesize each glass sample, the mineral or mineral mixture was ground to a fine powder $(<80 \mu \mathrm{m})$ using an agate mortar and pestle. Samples were loaded into platinum crucibles with lids, dried at $100^{\circ} \mathrm{C}$, and melted at atmospheric pressure for 3-4 hours: the oligoclase end-member was heated at $1550^{\circ} \mathrm{C}$ and all other samples were heated at $1600^{\circ} \mathrm{C}$. Platinum crucibles were used because they have a high melting temperature $\left(\sim 1770^{\circ} \mathrm{C}\right)$ and do not react with Fe-free samples. Quenching of molten samples was accomplished using an ice bath. Each synthesized glass was checked using a polarized petrographic microscope to confirm it was free of microlite crystals, which could add structure to the infrared spectrum.

\subsection{Glass Analyses}

[7] Glasses were characterized using electron microprobe analysis and two complementary Fourier transform infrared (FTIR) spectroscopy techniques: micro-reflectance and emission. Due to the potential compositional range and minor contaminants of the natural minerals used to synthesize the samples and possible alkali-loss during synthesis, glass compositions were determined at the University of Western Ontario with a JEOL JXA 8600 electron microprobe using a $15 \mathrm{kV}, 5 \mathrm{nA}$, and $20 \mu \mathrm{m}$ beam with wavelength dispersive spectroscopy and ZAF (atomic number/absorption/fluorescence) corrections. FTIR spectroscopy utilized two Nicolet Nexus 670 FTIR spectrometers, although the source, beamsplitter, detector, and sample chamber configuration differ as a function of the analysis technique used.

[8] Micro-specular reflectance spectra were acquired in the Experimental Analysis Laboratory using a Continu $\mu \mathrm{m}$ microscope (micro-FTIR) with Reflachromat objectives attached to the spectrometer, which uses a collimated Globar source, an XT-KBr beamsplitter, and an MCT-A detector (effective spectral range $650-4000 \mathrm{~cm}^{-1}, 2.5-$ $15.4 \mu \mathrm{m})$. For our analyses, a chip of each glass sample (typically $2-3 \mathrm{~mm}$ in diameter) was mounted in epoxy and polished to a flat surface with a $1 \mu \mathrm{m}$ finish using diamond paste. Each reflectance spectrum was measured at a spectral resolution of $4 \mathrm{~cm}^{-1}\left(\sim 2 \mathrm{~cm}^{-1}\right.$ sampling $)$ over a $100 \times$ $100 \mu \mathrm{m}$ area and ratioed to a gold standard. This technique is advantageous because it provides for analysis of small samples, allows for sample homogeneity to be tested on the micron scale, and has a much higher signal-to-noise ratio (SNR) than the emission measurements. However, this reflectance technique is not directly comparable to TIR airborne and spaceborne remote sensing of materials in natural environments, in which the surface materials provide the TIR source.

[9] Emission spectra were acquired and converted to absolute emissivity spectra following the methodology of Ruff et al. [1997]. At the IVIS Laboratory, this technique uses samples heated to $\sim 80^{\circ} \mathrm{C}$ as the TIR source, and measured using a $\mathrm{KBr}$ beamsplitter and a DTGS detector $\left(400-2000 \mathrm{~cm}^{-1}, 5.0-25.0 \mu \mathrm{m}\right)$ at a spectral resolution of $4 \mathrm{~cm}^{-1}\left(\sim 2 \mathrm{~cm}^{-1}\right.$ sampling). For our analyses, each sample consisted of several grams of glass particles ( $\geq 250 \mu \mathrm{m}$ sieve size, typically $\sim 2-3 \mathrm{~mm}$ diameter). The emission technique is advantageous because it effectively collects directionally-emitted radiance data, which are directly comparable to data acquired by remote sensing instruments [e.g., Christensen et al., 2000]; additionally, emission measurements can be made on many natural surfaces (e.g., samples with surficial coatings). The glass spectra were also compared with mineral end-member spectra and modeled spectra of mineral mixtures derived from the Thermal Emission Spectral Library (http://tes.asu.edu/ speclib/) [Christensen et al., 2000]. Spectra of mineral mixtures were modeled by convolving feldspar and quartz mineral spectra proportionate to each feldspar + quartz glass sample (i.e., each is a weighted average spectrum).

\section{Results and Discussion}

[10] TIR spectra of the glasses with the corresponding mineral and mineral mixture spectra are provided in Figure 1. Emissivity $(\varepsilon)$ spectra are very similar to the inverse of the reflectance (R) spectra as expected from Kirchhoff's Law $(\varepsilon=1-\mathrm{R})$ [e.g., Nicodemus, 1965; Hapke, 1993]. Although directional emissivity and specular reflectance are not inherently complementary measurements, the diffusely-scattered component from the polished, specular reflectance samples is insignificant, making Kirchhoff's Law applicable (as illustrated in Figure 1). The primary difference in the emissivity spectra derived from the two techniques is the diminished spectral contrast (i.e., shallower features) of the emission data. This effect is expected because each emission sample consisted of multiple glass particles, introducing a reflected component, which effectively mutes the contrast of the emissivity features [cf. Ramsey and Fink, 1999]. 


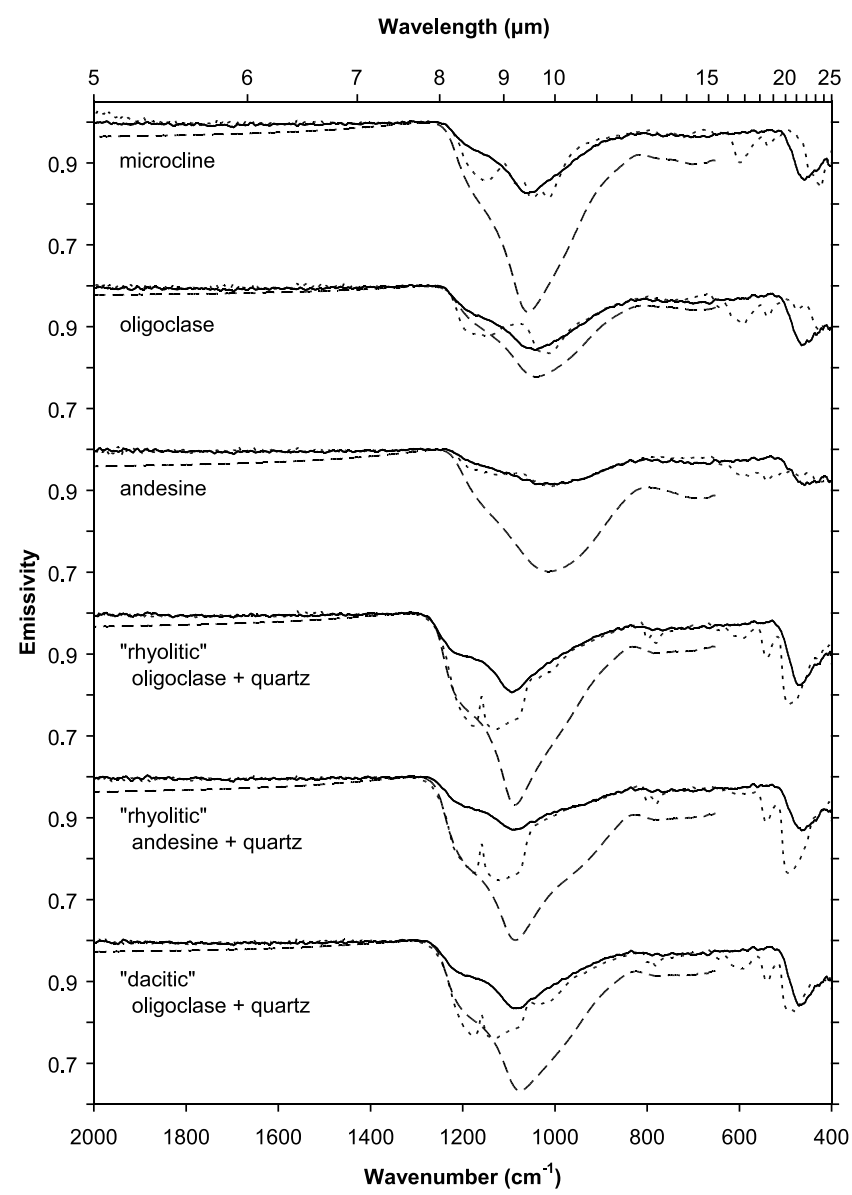

Figure 1. TIR emissivity spectra of synthesized glasses (solid lines), micro-specular reflectance spectra of synthesized glasses plotted as 1-R (long dashes), and emissivity spectra of corresponding crystalline materials (short dashes) derived from the ASU spectral library (http://tes.asu.edu/ speclib/index.html) [Christensen et al., 2000]. Spectra are offset for clarity, as indicated, but the spectral contrast has not been adjusted.

[11] The glass spectra show a shift in TIR reflectance maxima toward higher wavenumbers (shorter wavelengths) from andesine to simulated rhyolite (Table 1). This spectral shift is highly correlated with an increasing ratio of silicon to oxygen (Figure 2), a decreasing ratio of aluminum to oxygen (Figure 2), and a decreasing ratio of aluminum to silicon (not shown) [cf. Salisbury et al., 1991]. This shift is expressed in the glass emission data as a shift in reststrahlen band emissivity minima, which also occurs for crystalline silicates (Figure 1). Physical aspects of the semi-amorphous glass determine the overall shape of the TIR spectral features. For example, the broadness of each dominant spectral feature centered at $\sim 1060 \mathrm{~cm}^{-1}(9.4 \mu \mathrm{m})$ and the shoulder displayed at $\sim 1175-1200 \mathrm{~cm}^{-1}(8.3-8.5 \mu \mathrm{m})$ in each glass spectrum are attributed to specific stretching vibrations of Si-O and Al-O bonds [e.g., King et al., 2004; Michalski et al., 2005]. The features near $\sim 500 \mathrm{~cm}^{-1}(20.0 \mu \mathrm{m})$ are due to bending modes of the Si-O bonds [e.g., King et al., 2004]. Comparison of the glass and mineral spectra clearly illustrates that shoulders present in each glass spectrum are related to muting of significant mineral emissivity features (Figure 1), which occurs due to the disordering of silicate structures (i.e., depolymerization of tectosilicates).

\section{Implications for Remote Sensing of Earth and Mars}

[12] Volcanism is an important and ongoing geologic process on Earth. Volcanic glasses are associated with lava flows, lava domes, and pyroclastic materials ranging in composition from rhyolitic to basaltic and have been found to significantly affect TIR remote sensing spectral signatures [e.g., Kahle et al., 1988; Crisp et al., 1990; Realmuto et al., 1992; Ramsey and Fink, 1999; Byrnes et al., 2004; Ramsey and Dehn, 2004]. Enhanced knowledge of glass spectral characteristics relevant to these systems allows for better characterization of the distribution of surface chemistry within volcanic units and more accurate determination of micron-scale surface textures and coatings. Specifically, the muting of spectral features may be used to distinguish a glass from its crystalline counterpart, and the measured spectral shift may be used to distinguish glasses with different chemical compositions provided TIR data of sufficient spectral resolution. Additionally, glass is a better proxy for lava than crystalline minerals because both the glass and melt structures lack long-range order of crystal structures. Therefore, incorporating glass spectra into TIR spectral deconvolution algorithms will help to more accurately determine the chemistry of exposed melts on Earth (i.e., active lava flows and lava lakes).

[13] Volcanism has occurred extensively over the history of Mars [e.g., Carr, 1973], suggesting that abundant glass was likely produced. Lately, it has been suggested that volcanism has occurred significantly more recently than previously thought [e.g., Neukum et al., 2004; Hauber et al., 2005]. Given that volcanic glasses may last $10 \mathrm{~s}$ of Ma on Earth depending on their environment [Forsman, 1984; Friedman and Long, 1984] and are expected to survive longer in recent Martian history due to a paucity of surface water [Schultz and Mustard, 2004], it is reasonable to expect that Martian volcanic glasses may be detectable in high-resolution TIR emission data. In fact, a widespread but enigmatic silica-rich phase(s) has been documented on Mars as a component of "surface type 2" [Bandfield et al., 2000]. Possible candidates for this spectral end-member include rhyolitic glass $\left(\sim 74\right.$ wt. $\left.\% \mathrm{SiO}_{2}\right)$ [e.g., Bandfield et al., 2000; Hamilton et al., 2003], clays [e.g., Wyatt and McSween, 2002, 2003; Wyatt et al., 2004], silica-rich coatings [e.g., Kraft et al., 2003], zeolites [Ruff, 2004], and shocked feldspars [Staid et al., 2004; Johnson et al., 2006]. Various investigators have found potential analog materials present within Martian meteorites [e.g., Hamilton et al., 1997; Minitti et al., 2002], although the glass components are typically too small to obtain TIR emission spectra sufficiently pure to serve as end-members for deconvolution of Mars TIR data.

[14] Examination of glasses is important for mapping the composition of materials and understanding volcanic systems on Earth and Mars. Using remote sensing to detect and identify the distribution of glasses has significant implications for better understanding the petrology and volcanic processes on planetary surfaces, including Earth. The sam- 


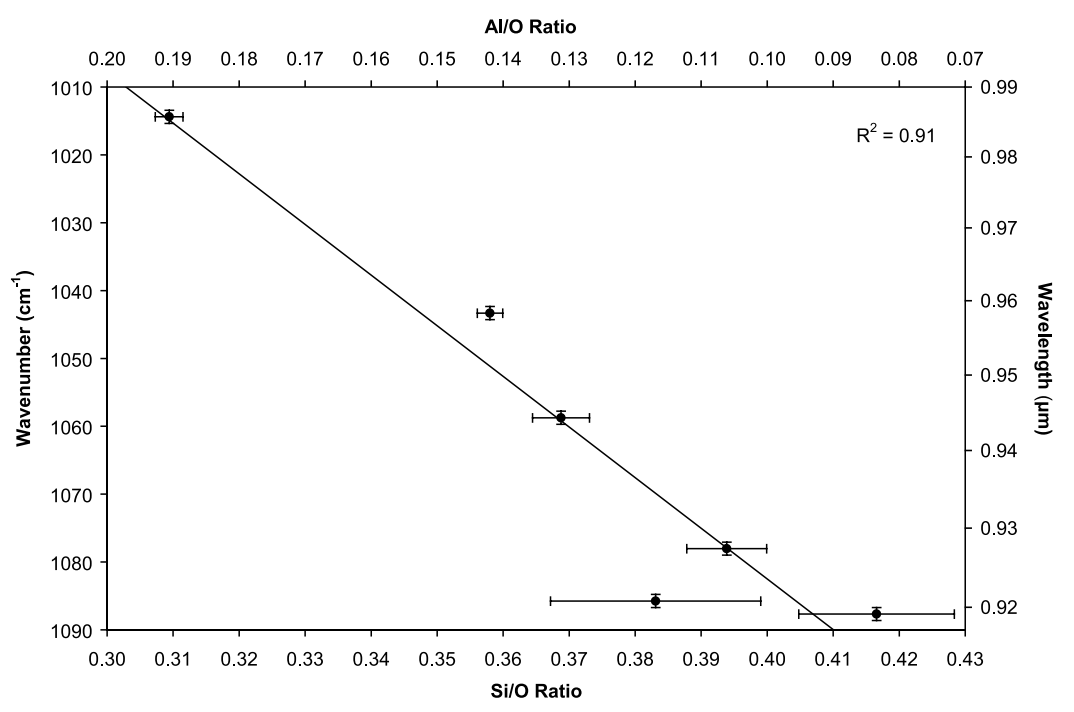

Figure 2. Compositional control on TIR spectra of glasses. The wavenumber of the measured reflectance maximum is plotted as a function of the ratio of silicon to oxygen and aluminum to oxygen for each glass sample based on microprobe analysis; reststrahlen band emissivity minimum values show the same general trend (Figure 1 and Table 1). Higher proportions of silicon and lower proportions of aluminum are highly correlated with a spectral shift to higher wavenumbers (shorter wavelengths).

ples synthesized in this study are simplified analogs to glasses associated with evolved volcanic systems such as silicic lava domes, which are typically rich in silica and incompatible elements. Future work is focused on two objectives. First, we will conduct similar experiments, but expand the compositional range of glasses examined, compare the synthesized glasses with natural glasses and other amorphous materials, and use these spectra to analyze TIR remote sensing data of surficial materials. Second, new hardware is being installed at the IVIS Laboratory that will allow us to directly acquire TIR emission spectra of silicate melts and glasses at temperatures up to $1750^{\circ} \mathrm{C}$.

[15] Acknowledgments. The authors would like to thank Céleste Dufresne for conducting the microprobe analysis. The manuscript was improved based on comments and reviews by Josh Bandfield, Jeff Johnson, Laszlo Keszthelyi, and an anonymous reviewer. Funding for this research was made possible through grants to MSR from the Petrology and Geochemistry Program of the National Science Foundation (grant 0309631) and from the ASTER science team project of the National Aeronautics and Space Administration (grant NNG04GO69G) and grants to PLK from the Canadian National Science and Engineering Research Council and the Canada Foundation for Innovation.

\section{References}

Bandfield, J. L., V. E. Hamilton, and P. R. Christensen (2000), A global view of Martian surface compositions from MGS-TES, Science, 287, $1626-1630$

Byrnes, J. M., M. S. Ramsey, and D. A. Crown (2004), Surface unit characterization of the Mauna Ulu flow field, Kilauea Volcano, Hawai'i, $\mathrm{i}$, using integrated field and remote sensing analyses, J. Volcanol. Geotherm. Res., 135, 169-193, doi:10.1016/j.jvolgeores.2003.12.016.

Carr, M. H. (1973), Volcanism on Mars, J. Geophys. Res., 78, 4049-4062.

Christensen, P. R., J. L. Bandfield, V. E. Hamilton, D. A. Howard, M. D. Lane, J. L. Piatek, S. W. Ruff, and W. L. Stefanov (2000), A thermal emission spectral library of rock-formation minerals, J. Geophys. Res., 105, 9735-9739.

Crisp, J., A. B. Kahle, and E. A. Abbott (1990), Thermal infrared spectral character of Hawaiian basaltic glasses, J. Geophys. Res., 95, 21,65721,669 .

Forsman, N. F. (1984), Durability and alteration of some Cretaceous and Paleocene pyroclastic glasses in North Dakota, J. Non Cryst. Solids, 67, $449-461$.
Friedman, I., and W. Long (1984), Volcanic glasses, their origins and alteration processes, J. Non Cryst. Solids, 67, 127-133.

Hamilton, V. E., P. R. Christensen, and H. Y. McSween (1997), Determination of Martian meteorite lithologies and mineralogies using vibrational spectroscopy, J. Geophys. Res., 102, 25,593-25,603.

Hamilton, V. E., M. B. Wyatt, H. Y. McSween, and P. R. Christensen (2001), Analysis of terrestrial and Martian volcanic compositions using thermal emission spectroscopy: 2. Application to Martian surface spectra from the Mars Global Surveyor Thermal Emission Spectrometer, J. Geophys. Res., 106, 14,733-14,746.

Hamilton, V. E., P. R. Christensen, and J. L. Bandfield (2003), Volcanism or aqueous alteration on Mars?, Nature, 421, 711-712.

Hapke, B. (1993), Theory of Reflectance and Emittance Spectroscopy, 455 pp., Cambridge Univ. Press, New York.

Hauber, E. S., et al. (2005), Discovery of a flank caldera and very young glacial activity at Hecates Tholus, Mars, Nature, 434, 356-361, doi:10.1038/nature03423.

Johnson, J. R., F. Hörz, P. G. Lucey, and P. R. Christensen (2002), Thermal infrared spectroscopy of experimentally shocked anorthosite and pyroxenite: Implications for remote sensing of Mars, J. Geophys. Res., 107(E10), 5073, doi:10.1029/2001JE001517.

Johnson, J. R., F. Hörz, and M. I. Staid (2003), Thermal infrared spectroscopy and modeling of experimentally shocked plagioclase feldspars, Am. Mineral., 88, 1575-1582.

Johnson, J. R., M. I. Staid, T. N. Titus, and K. Becker (2006), Shocked plagioclase signatures in Thermal Emission Spectrometer data of Mars, Icarus, 180, 60-74.

Kahle, A. B., A. R. Gillespie, E. A. Abbott, M. J. Abrams, R. E. Walker, G. Hoover, and J. P. Lockwood (1988), Relative dating of Hawaiian lava flows using multispectral thermal infrared images: A new tool for geologic mapping of young volcanic terranes, J. Geophys. Res., 93, 15,239-15,251.

King, P. L., P. F. McMillan, and G. M. Moore (2004), Infrared spectroscopy of silicate glasses with application to natural systems, in Infrared Spectroscopy in Geochemistry, Exploration Geochemistry, and Remote Sensing, Mineral. Assoc. of Can. Short Course Ser, vol. 33, edited by P. L. King, M. S. Ramsey, and G. A. Swayze, pp. 93-133, Mineral. Assoc. of Can., Ottawa.

Koeppen, W. C., and V. E. Hamilton (2005), Discrimination of glass and phyllosilicate minerals in thermal infrared data, J. Geophys. Res., 110, E08006, doi:10.1029/2005JE002474.

Kraft, M. D., J. R. Michalski, and T. G. Sharp (2003), Effects of pure silica coatings on thermal emission spectra of basaltic rocks: Considerations for Martian surface mineralogy, Geophys. Res. Lett., 30(24), 2288, doi:10.1029/2003GL018848.

Lyon, R. J. P. (1965), Analysis of rocks by spectral infrared emission (8 to 25 microns), Econ. Geol., 60, 715-736. 
Michalski, J. R., M. D. Kraft, T. G. Sharp, L. B. Williams, and P. R. Christensen (2005), Mineralogical constraints on the high-silica Martian surface component observed by TES, Icarus, 174, 161-177.

Minitti, M. E., J. F. Mustard, and M. J. Rutherford (2002), Effects of glass content and oxidation on the spectra of SNC-like basalts: Applications to Mars remote sensing, J. Geophys. Res., 107(E5), 5030, doi:10.1029/ 2001JE001518.

Nash, D. B., and J. W. Salisbury (1991), Infrared reflectance spectra (2.2$15 \mu \mathrm{m})$ of plagioclase feldspars, Geophys. Res. Lett., 18, 1151-1154.

Neukum, G., et al. (2004), Recent and episodic volcanic and glacial activity on Mars revealed by the High Resolution Stereo Camera, Nature, 432, 971-979, doi:10.1038/nature03231.

Nicodemus, F. E. (1965), Directional reflectance and emissivity of an opaque surface, Appl. Opt., 4, 767-773.

Ramsey, M. S., and J. Dehn (2004), Spaceborne observations of the 2000 Bezymianny, Kamchatka eruption: The integration of high-resolution ASTER data into near real-time monitoring using AVHRR, J. Volcanol. Geotherm. Res., 135, 127-146.

Ramsey, M. S., and J. H. Fink (1999), Estimating silicic lava vesicularity with thermal remote sensing: A new technique for volcanic mapping and monitoring, Bull. Volcanol., 61, 32-39.

Realmuto, V. J., K. Hon, A. B. Kahle, E. A. Abbott, and D. C. Pieri (1992), Multispectral thermal infrared mapping of the 1 October 1988 Kupaianaha flow field, Kilauea Volcano, Hawaii, Bull. Volcanol., 55, 33-44.

Ruff, S. W. (2004), Spectral evidence for zeolite in the dust on Mars, Icarus, $168,131-143$.

Ruff, S. W., P. R. Christensen, P. W. Barbera, and D. L. Anderson (1997), Quantitative thermal emission spectroscopy of minerals: A laboratory technique for measurement and calibration, J. Geophys. Res., 102, 14,899-14,913.

Salisbury, J. W., L. S. Walter, N. Vergo, and D. M. D’Aria (1991), Infrared

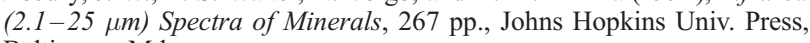
Baltimore, Md.
Schultz, P. H., and J. F. Mustard (2004), Impact melts and glasses on Mars, J. Geophys. Res., 109, E01001, doi:10.1029/2002JE002025.

Staid, M. I., J. R. Johnson, and L. R. Gaddis (2004), Analysis of Mars Thermal Emission Spectrometer data using large mineral reference libraries, Lunar Planet. Sci. [CD-ROM], XXXV, abstract 1778.

Vincent, R. K., and F. Thomson (1972), Spectral compositional imaging of silicate rocks, J. Geophys. Res., 77, 2465-2472.

Walter, L. S., and J. W. Salisbury (1989), Spectral characterization of igneous rocks in the 8- to $12-\mu \mathrm{m}$ region, J. Geophys. Res., 94, 92039213.

Wyatt, M. B., and H. Y. McSween (2002), Spectral evidence for weathered basalt as an alternative to andesite in the northern lowlands of Mars, Nature, 417, 263-266.

Wyatt, M. B., and H. Y. McSween (2003), Volcanism or aqueous alteration on Mars? (reply), Nature, 421, 712-713.

Wyatt, M. B., V. E. Hamilton, H. Y. McSween Jr., P. R. Christensen, and L. A. Taylor (2001), Analysis of terrestrial and Martian volcanic compositions using thermal emission spectroscopy: 1. Determination of mineralogy, chemistry, and classification strategies, J. Geophys. Res., 106, 14,711-14,732.

Wyatt, M. B., H. Y. McSween, K. L. Tanaka, and J. W. Head (2004), Global geologic context for rock types and surface alteration on Mars, Geology, $32,645-648$

J. M. Byrnes, Astrogeology Team, U.S. Geological Survey, 2255 North Gemini Drive, Flagstaff, AZ 86001-1637, USA. (jmbyrnes@usgs.gov)

P. L. King, Department of Earth Sciences, University of Western Ontario, London, ON, Canada N6A 587.

R. J. Lee and M. S. Ramsey, Department of Geology and Planetary Science, University of Pittsburgh, Pittsburgh, PA 15260-3332, USA. 